\title{
$N$-Nonyloxypentyl-L-Deoxynojirimycin Inhibits Growth, Biofilm Formation and Virulence Factors Expression of Staphylococcus aureus
}

\author{
Eliana De Gregorio ${ }^{1, *(1)}$, Anna Esposito ${ }^{2}\left(\mathbb{D}\right.$, Adriana Vollaro ${ }^{1}\left(\mathbb{D}\right.$, Maria De Fenza ${ }^{2}(0)$ \\ Daniele D'Alonzo ${ }^{2}$, Antonella Migliaccio ${ }^{3}$, Vita Dora Iula ${ }^{4}$, Raffaele Zarrilli ${ }^{3}{ }^{\circ}$ and \\ Annalisa Guaragna 2,*(D) \\ 1 Department of Molecular Medicine and Medical Biotechnology, University of Naples Federico II, \\ Via S. Pansini 5, 80131 Naples, Italy; vollaroadriana@libero.it \\ 2 Department of Chemical Sciences, University of Naples Federico II, Via Cintia, 80126 Naples, Italy; \\ anna.esposito5@unina.it (A.E.); maria.defenza@unina.it (M.D.F.); daniele.dalonzo@unina.it (D.D.) \\ 3 Department of Public Health, University of Naples Federico II, Via S. Pansini 5, 80131 Naples, Italy; \\ antonella.migliaccio10@gmail.com (A.M.); rafzarri@unina.it (R.Z.) \\ 4 Complex Operative Unit of Clinical Pathology, “Ospedale del Mare-ASL NA1 Centro”, 80131 Naples, Italy; \\ dora.iula@gmail.com \\ * Correspondence: edegrego@unina.it (E.D.G.); annalisa.guaragna@unina.it (A.G.)
}

Received: 28 May 2020; Accepted: 24 June 2020; Published: 26 June 2020

\begin{abstract}
Staphylococcus aureus is one of the major causes of hospital- and community-associated bacterial infections throughout the world, which are difficult to treat due to the rising number of drug-resistant strains. New molecules displaying potent activity against this bacterium are urgently needed. In this study, D- and L-deoxynojirimycin (DNJ) and a small library of their $N$-alkyl derivatives were screened against S. aureus ATCC 29213, with the aim to identify novel candidates with inhibitory potential. Among them, $\mathrm{N}$-nonyloxypentyl-L-DNJ (L-NPDNJ) proved to be the most active compound against S. aureus ATCC 29213 and its clinical isolates, with the minimum inhibitory concentration (MIC) value of $128 \mu \mathrm{g} / \mathrm{mL}$. L-NPDNJ also displayed an additive effect with gentamicin and oxacillin against the gentamicin- and methicillin-resistant $S$. aureus isolate 00717. Sub-MIC values of L-NPDNJ affected S. aureus biofilm development in a dose-dependent manner, inducing a strong reduction in biofilm biomass. Moreover, real-time reverse transcriptase PCR analysis revealed that L-NPDNJ effectively inhibited at sub-MIC values the transcription of the spa, hla, hlb and sea virulence genes, as well as the agrA and saeR response regulator genes.
\end{abstract}

Keywords: antimicrobial agents; antibiofilm agents; anti-virulence agents; deoxynojirimycin (DNJ); Staphylococcus aureus; iminosugars

\section{Introduction}

Staphylococcus aureus is an important human pathogen responsible for a variety of communityand healthcare-associated infections [1,2], which are difficult to treat and to eradicate because of the acquisition of multiple antibiotic resistance [3] and biofilm growth of this organism on implantable medical devices [4]. S. aureus produces several virulence factors, such as adhesins [5,6], secreted toxins and extracellular enzymes [7-9], which contribute to biofilm growth and host damage during infection [7-9]. The rapid emergence of increasingly resistant $S$. aureus strains [1-3] has led to the necessity to develop novel therapeutic agents against persistent infections caused by this organism $[1,4,10,11]$.

Iminosugars are natural or synthetic sugar analogues having an amino function in place of the endocyclic oxygen of the corresponding carbohydrate [12]. Due to their excellent ability to 
inhibit and/or enhance the catalytic properties of ubiquitous carbohydrate processing enzymes, such as glycosidases and glycosyltransferases, iminosugars represent the most promising class of glycomimetics, exhibiting broad-spectrum therapeutic potential $[13,14]$. Three iminosugar-based drugs (Figure 1A) are currently marketed for treating type II diabetes (Glyset ${ }^{\circledR}$ ) and lysosomal storage disorders, including Gaucher and Niemann-Pick diseases type C (Zavesca ${ }^{\circledR}, N$-butyl- deoxynojirimycin, NBDNJ) and Fabry diseases (Galafold ${ }^{\circledR}$, deoxygalactonojirimycin, DGJ) [12,13,15]. In addition, a variety of other iminosugars have been proposed as therapeutic candidates against malignancies [16], viral infections [17, 18] and other genetic disorders, including cystic fibrosis [19-22]. Conversely, iminosugars have displayed only in a few cases efficacy against bacterial pathogens (Figure 1B). Nojirimycin (NJ) exhibited antibacterial activity against Xanthomonas oryzae, Shigella flexneri and Mycobacterium smegmatis ATCC 607 [23], while deoxynojirimicyn (DNJ) was found to inhibit Streptococcus mutans biofilm formation [24-26]. Other modified iminosugars such as Batzellaside A and Bulgecin A held interesting properties against Staphylococcus epidermidis and Gram-negative bacteria, respectively [23]. Eventually, selected piperidine and indolizidine iminosugars were found to inhibit the early biofilm formation of Pseudomonas aeruginosa [27].

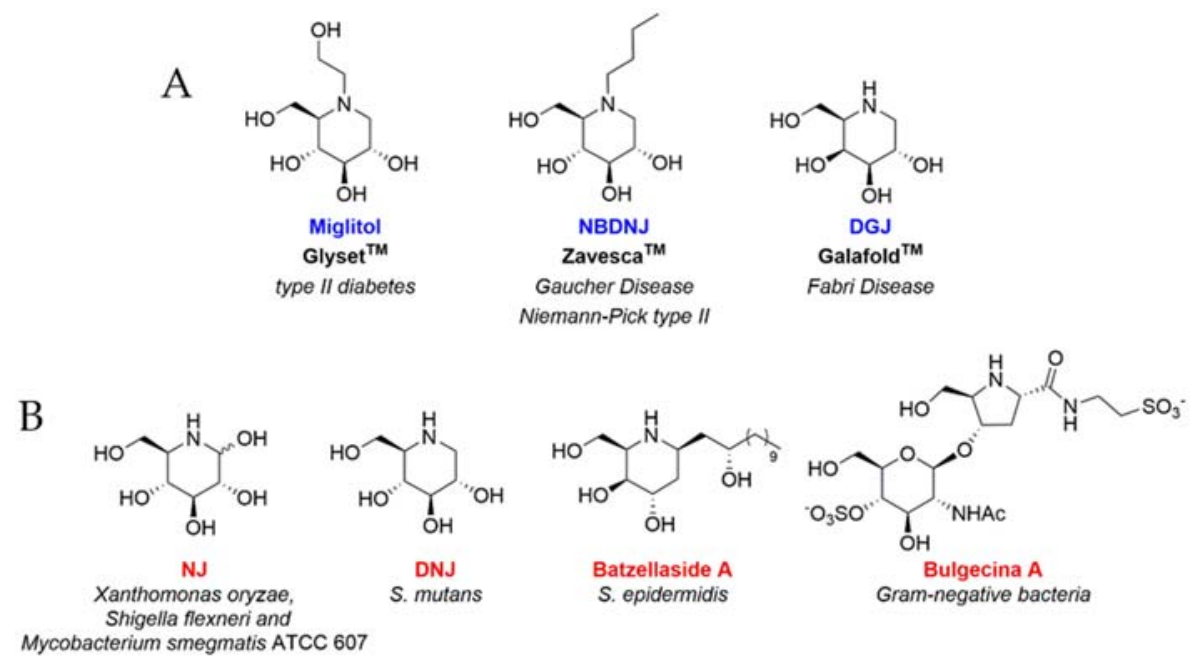

Figure 1. (A) Iminosugar-based drugs on the market. (B) Iminosugars showing antibacterial activity.

Despite their powerful pharmacological activity, the access of iminosugars to clinics is hampered in many cases by the limited selectivity in vivo, mainly owing to the side inhibition of various off target glycosidases. In order to balance biological activity and toxicity, many structural modifications have been proposed over recent years [28]. Among the most important elements so far identified, $N$-alkylation of iminosugars is known to considerably enhance the target selectivity [12]. On the other hand, changes in the configuration of iminosugar stereocenters have often provided unexpected yet promising results [29]. Particularly L-iminosugars, which were non-superimposable mirror images of the corresponding D-iminosugars, showed higher selectivity towards specific enzymes [21,30,31] and an even more interesting pharmacological potential towards several diseases than their D-enantiomers [20,21,32-34]. Among L-iminosugars with a gluco configuration, our recent findings highlighted the potential of L-NBDNJ (the enantiomer of the iminosugar drug D-NBDNJ, Zavesca ${ }^{\circledR}$ ) as a promising and selective new candidate for the combination therapy of Pompe disease [34]. Moreover, L-NBDNJ and its congeners showed interesting pharmacological properties as anti-inflammatory agents in cystic fibrosis [21,22].

In the present study, we analyzed the inhibition of $S$. aureus growth by L-DNJ and its $\mathrm{N}$-alkylated derivatives (Figure 2) and the effects on the biofilm formation and virulence factors expression of S. aureus of N-nonyloxypentyl-1-DNJ (l-NPDNJ) (Figure 2), the iminosugar enantiomer showing the highest antibacterial activity against $S$. aureus. 


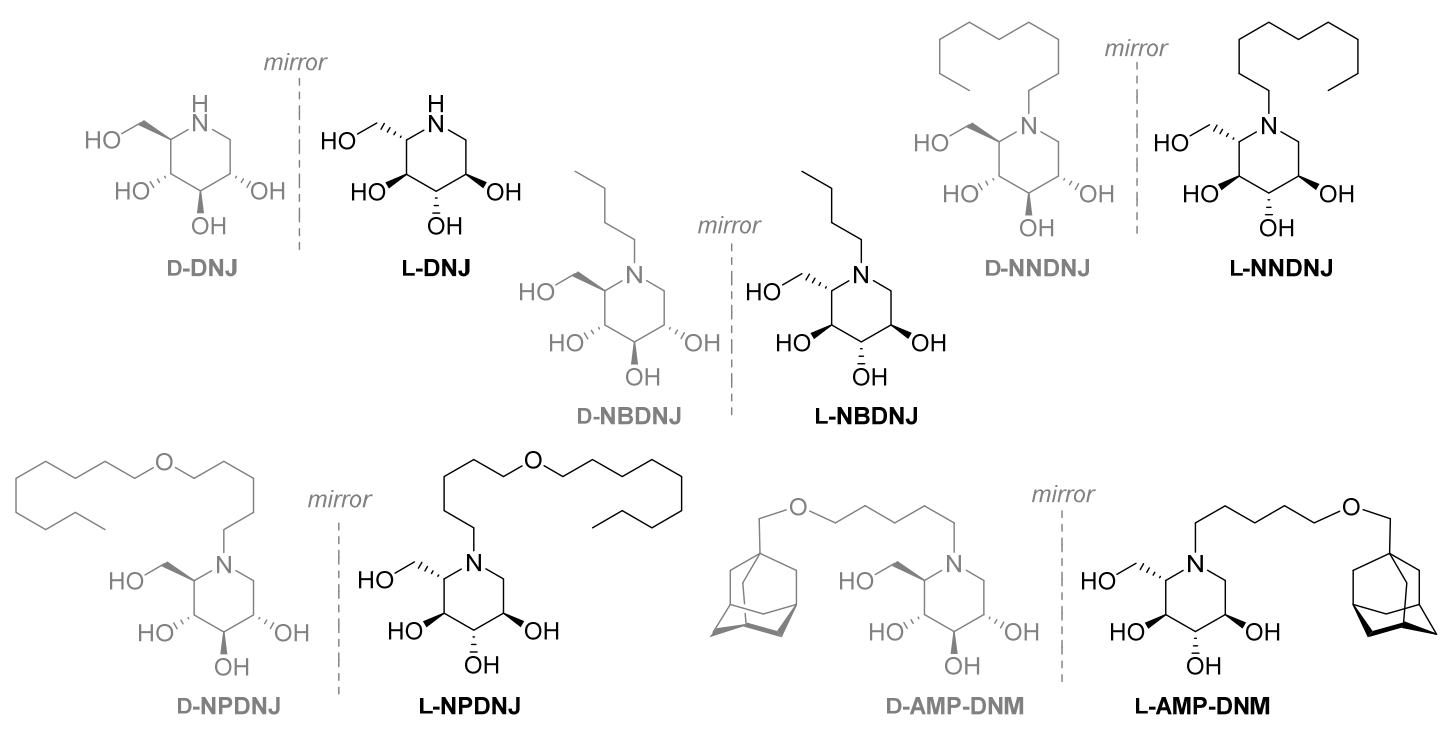

Figure 2. D- and L-deoxyiminosugars studied in this work. DNJ, deoxynojirimycin; NBDNJ, N-butyl DNJ; NNDNJ, N-nonyl DNJ; NPDNJ, N-nonyloxypentyl DNJ; AMP-DNM, N-[5-(adamantan-1-ylmethoxy) pentyl] -1-DNJ.

\section{Results and Discussion}

\subsection{Antimicrobial Activity of D- and L-DNJ and of A Library of Their N-Alkyl Derivatives}

The synthesis of unnatural L-DNJ was accomplished exploiting a de novo previously reported methodology [34-36]. $N$-alkylation of L-DNJ, as well as of D-DNJ, provided the corresponding $N$-alkylated derivatives as previously described (Figure 2) [21].

To analyze the effect of the small library of deoxyiminosugars in both enantiomeric forms on the growth of S. aureus ATCC 29213, the minimum inhibitory concentration (MIC) and minimum bactericidal concentration (MBC) were determined by a broth microdilution assay (Table 1).

Table 1. Minimum inhibitory concentration (MIC) $(\mu \mathrm{g} / \mathrm{mL})$ and minimum bactericidal concentration $(\mathrm{MBC})(\mu \mathrm{g} / \mathrm{mL})$ values of $\mathrm{D}$ - and L-DNJ and their $N$-alkyl derivatives against S. aureus ATCC 29213.

\begin{tabular}{cccc}
\hline Entry & Compound & MIC & MBC \\
\hline 1 & D-DNJ & $>1000$ & $>1000$ \\
2 & L-DNJ & $>1000$ & $>1000$ \\
3 & D-NBDNJ & $>1000$ & $>1000$ \\
4 & L-NBDNJ & $>1000$ & $>1000$ \\
5 & D-NNDNJ & 1000 & $>1000$ \\
6 & L-NNDNJ & 1000 & $>1000$ \\
7 & D-NPDNJ & 256 & 1000 \\
8 & L-NPDNJ & 128 & 256 \\
9 & D-AMP-DNM & 256 & $>1000$ \\
10 & L-AMP-DNM & 512 & $>1000$ \\
11 & Gentamicin & 1 & 2 \\
\hline
\end{tabular}

Abbreviations: MIC, minimum inhibitory concentration; MBC, minimum bactericidal concentration; DNJ, deoxynojirimycin.

Previous studies showed that D-DNJ has antimicrobial activity against $S$. mutans [24,25]. Conversely, DNJ and NBDNJ in both enantiomeric forms were inactive against S. aureus ATCC 29213 cells (Table 1, entries 1 to 4). Both enantiomers of NNDNJ (entries 5 and 6) showed very low antimicrobial activity at the MIC value of $1000 \mu \mathrm{g} / \mathrm{mL}$. D- and L-AMP-DNM (entries 9 and 10) and D-NPDNJ (entry 7) showed poor antimicrobial activity, with MIC values ranging from 256 to $512 \mu \mathrm{g} / \mathrm{mL}$. The antibacterial activity of L-NPDNJ (entry 8) was found to be the best one in this series, with an MIC value of $128 \mu \mathrm{g} / \mathrm{mL}$ and 
an MBC value of $256 \mu \mathrm{g} / \mathrm{mL}$. The data clearly suggest a role of the lipophilicity in the antimicrobial potential of the examined iminosugars, as only the more hydrophobic piperidines showed an inhibitory effect. Differently from previous results [21,34], sugar chirality did not appear to have a major role in the antibacterial activity of the corresponding iminosugars. Even in the case of NPDNJ, only a slight preference for the L-enantiomer was detected. In addition, it should be noted that the antimicrobial activity was lower than that of the marketed drug gentamicin, used as the reference compound (entry 11). The absence of cytotoxicity for all the tested compounds has been previously evaluated [21].

Then, we analyzed the antimicrobial activity of L-NPDNJ against a panel of ten $S$. aureus clinical isolates showing different antibiotic resistance profiles (Table S1). The MIC and MBC values of L-NPDNJ against $S$. aureus clinical isolates were identical to those obtained against the reference $S$. aureus ATCC 29213 strain (Table S2). Moreover, all S. aureus clinical isolates and the S. aureus ATCC 29213 strain showed an MBC/MIC ratio of 2 for L-NPDNJ (Table S2), thus indicating that this compound exhibited bactericidal activity [37].

The bactericidal effect induced by L-NPDNJ was evaluated also by time kill studies. The bacteria were challenged with $1 \times$ MIC $(128 \mu \mathrm{g} / \mathrm{mL}), 2 \times \mathrm{MIC}(256 \mu \mathrm{g} / \mathrm{mL})$ or $4 \times \mathrm{MIC}(512 \mu \mathrm{g} / \mathrm{mL})$ of L-NPDNJ and the time course of bacterial growth inhibition was followed by monitoring the viable bacterial counts (Figure 3).

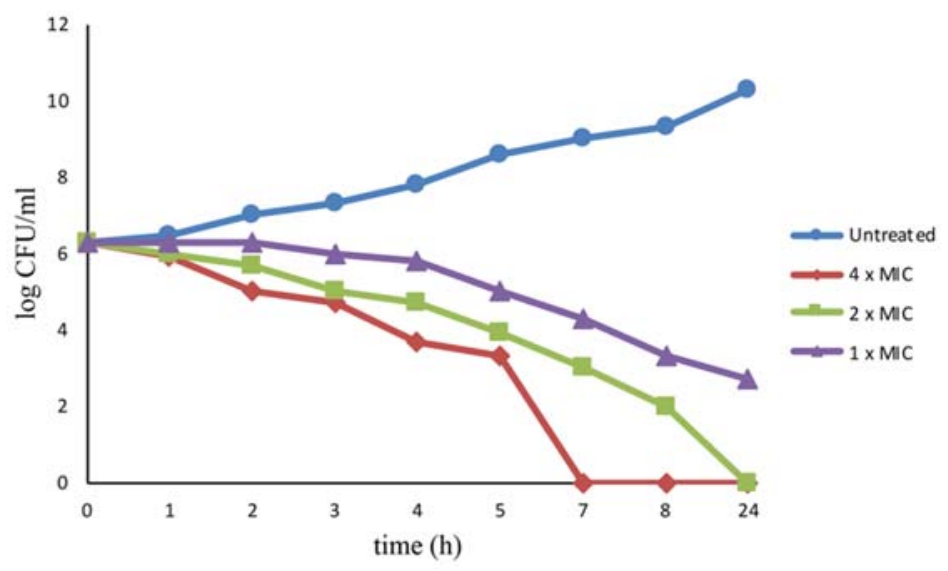

Figure 3. Killing kinetics for S. aureus ATCC 29213 following treatment with the L-NPDNJ. Growth kinetics were monitored following exposure to L-NPDNJ at $1 \times$ MIC, $2 \times$ MIC and $4 \times$ MIC.

At the concentration of $512 \mu \mathrm{g} / \mathrm{mL}, \mathrm{L}-\mathrm{NPDNJ}$ completely killed the strain after incubation for $7 \mathrm{~h}$. No viable S. aureus ATCC 29213 cells were recovered after 24-hours exposure at $256 \mu \mathrm{g} / \mathrm{mL}(2 \times \mathrm{MIC})$. L-NPDNJ at the concentration of $128 \mu \mathrm{g} / \mathrm{mL}$ did not completely kill the strain after incubation for $24 \mathrm{~h}$, although the concentration of the bacteria was reduced to $2 \times 10^{3} \mathrm{CFU} / \mathrm{mL}$ after L-NPDNJ treatment for $8 \mathrm{~h}$ (Figure 3). The time kill kinetic studies confirmed the efficacy of compound L-NPDNJ against S. aureus.

In subsequent experiments, we studied whether L-NPDNJ may have combination effects when mixed with other compounds. To define the nature of the interaction (antagonistic, indifferent or synergistic) between enantiomeric species, the combination effect mixing D- and L-NPDNJ was evaluated by a broth microdilution checkerboard assay, using the fractional inhibitory concentration method described by Hall et al. [38]. When both enantiomers were combined in equimolar amounts, a two-fold reduction in the MIC value for both D-NPDNJ (from 256 to $128 \mu \mathrm{g} / \mathrm{mL}$ ) and L-NPDNJ (from 128 to $64 \mu \mathrm{g} / \mathrm{mL}$ ) was observed, indicating an enhancement of the antimicrobial activity as a consequence of an additive effect by the racemic mixture (fractional inhibitory concentration index $($ FICI) value $=1$ ). To assess whether L-NPDNJ was able to potentiate or restore the antibacterial activity of currently available antibiotics against $S$. aureus, the iminosugar was evaluated in combinations with gentamicin and oxacillin against the clinical isolate S. aureus 00717 [39], which was resistant to both antimicrobials (Table S1). The checkerboard microdilution assay showed that L-NPDNJ markedly 
lowered the MIC values of gentamicin (from 256 to $8 \mu \mathrm{g} / \mathrm{mL}$ ) and oxacillin (from 128 to $1 \mu \mathrm{g} / \mathrm{mL}$ ) against the bacterial strain (Table 2). These results demonstrated that the combination of L-NPDNJ with either gentamicin or oxacillin had an additive effect, as the FICI values were 0.5078 and 0.5312 , respectively (Table 2). Interestingly, our data revealed that L-NPDNJ was able to restore the efficacy of oxacillin against methicillin-resistant $S$. aureus strains, while improving the antimicrobial activity of gentamicin.

Table 2. Additive effect of L-NPDNJ with antibiotics against S. aureus isolate 00717 .

\begin{tabular}{ccccc}
\hline Bacterial Strain & Combination & MIC $^{\mathbf{a}}(\mu \mathrm{g} / \mathrm{mL})$ & MIC $^{\mathrm{c}}(\mu \mathrm{g} / \mathrm{mL})$ & FICI \\
\hline \multirow{2}{*}{ S. aureus 00717 } & L-NPDNJ/oxacillin & $128 / 128$ & $64 / 1$ & 0.5078 \\
& L-NPDNJ/gentamicin & $128 / 256$ & $64 / 8$ & 0.5312 \\
\hline
\end{tabular}

$\mathrm{MIC}^{\mathrm{a}}$, MIC of one sample alone; $\mathrm{MIC}^{\mathrm{c}}$, MIC of samples in combination; FICI, fractional inhibitory concentration index.

\subsection{Effects of $\mathrm{L}-N P D N J$ on Formation of S. Aureus Biofilm}

Most S. aureus strains form biofilms on several biotic and abiotic surfaces, and this greatly contributes to the pathogenicity of this species [5,6]. To assess whether the antimicrobial iminosugar L-NPDNJ affected the biofilm formation of the S. aureus ATCC 29213 strain, the biofilm biomass of S. aureus ATCC 29213 cells treated with increasing concentrations of L-NPDNJ in static conditions at $37^{\circ} \mathrm{C}$ was analyzed using abiotic crystal violet staining. Sub-inhibitory concentrations of L-NPDNJ were able to reduce the biofilm formation of S. aureus ATCC 29213 compared with the untreated control in a dose-dependent manner (Figure 4).

A

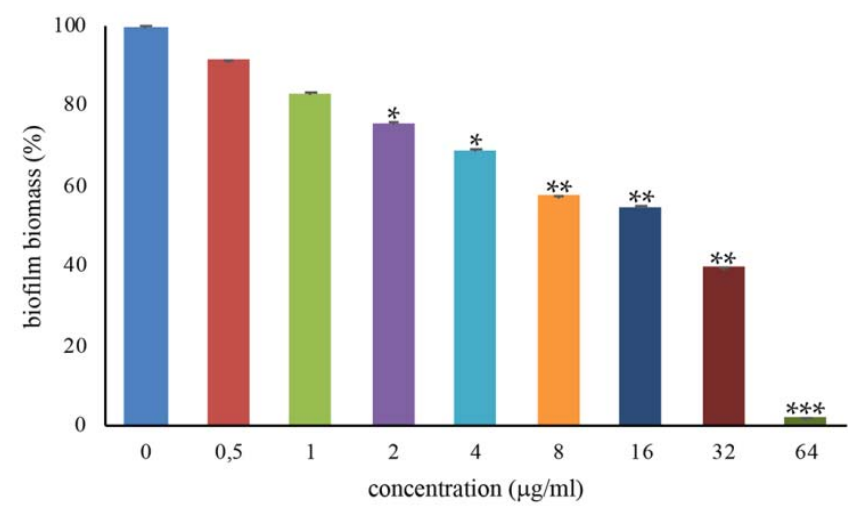

B

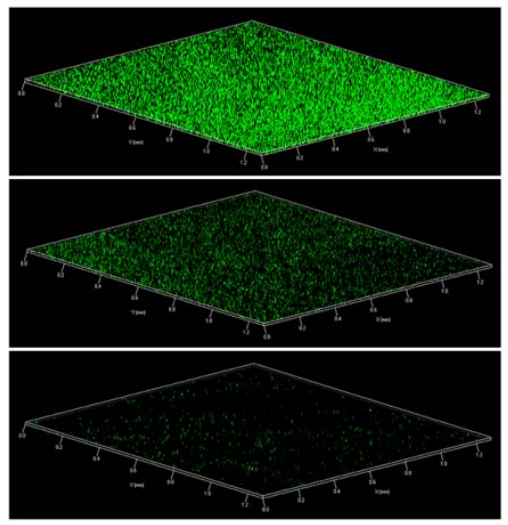

Figure 4. Inhibition of S. aureus ATCC29213 biofilm formation with L-NPDNJ. (A) Biofilm was quantified after crystal violet staining. Values are presented as means \pm SDs. Asterisks indicate statistically significant differences between treated and untreated biofilms $\left({ }^{*} p<0.05,{ }^{* *} p<0.01,{ }^{* * *} p<0.001\right)$. (B) Confocal laser scanning microscopy (CLSM) analysis of the biofilm formed in the absence (upper panel) or presence of L-NPDNJ at the concentrations of 32 (middle panel) and $64 \mu \mathrm{g} / \mathrm{mL}$ (inferior panel).

In particular, a reduction of $98 \%, 60 \%$ and $45 \%$ in the biofilm biomass of S. aureus ATCC 29213 was found at the L-NPDNJ concentrations 64,32 and $16 \mu \mathrm{g} / \mathrm{mL}$, corresponding to $1 / 2 \times \mathrm{MIC}, 1 / 4 \times \mathrm{MIC}$ and $1 / 8 \times \mathrm{MIC}$, respectively. To determine whether the inhibitory effect on biofilm formation was related to growth inhibition, planktonic growth was measured in the same conditions used in the biofilm assay. At the concentrations tested in the biofilm assay, L-NPDNJ did not affect the planktonic growth of the S. aureus ATCC 29213 strain (data not shown).

There are currently only a few papers focusing on the antibiofilm activity of iminosugars. Strus et al. showed the inhibition of P. aeruginosa biofilm formation by specific iminosugars, probably owing to the interference with the biosynthesis of extracellular polymeric substances [27]. However, this effect was found to occur only at high concentrations. Similarly, D-DNJ was reported to inhibit 
adherence and biofilm formation by $S$. mutans, reducing the expression of the glucosyltransferase genes responsible for the sugar-dependent $S$. mutans biofilm formation [24-26]. In contrast, pyrrolidine-based hamamelitannin analogues are inactive as antibiofilm agents [40].

In conclusion, sub-MIC values of L-NPDNJ exhibited no bactericidal activity against $S$. aureus but affected S. aureus biofilm formation in a dose-dependent manner, inducing a strong reduction in the biofilm biomass.

\subsection{Antivirulence Activity of L-NPDNJ in S. Aureus ATCC 29213}

Therapeutic agents able to reduce $S$. aureus virulence, especially toxin production, would help to control infections caused by multidrug-resistant strains [10,11]. In order to investigate the effect of L-NPDNJ on S. aureus virulence genes [7], the expression levels of 16 virulence genes were measured by reverse transcription real-time PCR (qRT-PCR) in S. aureus ATCC 29213, following treatment with L-NPDNJ (Figure 5).

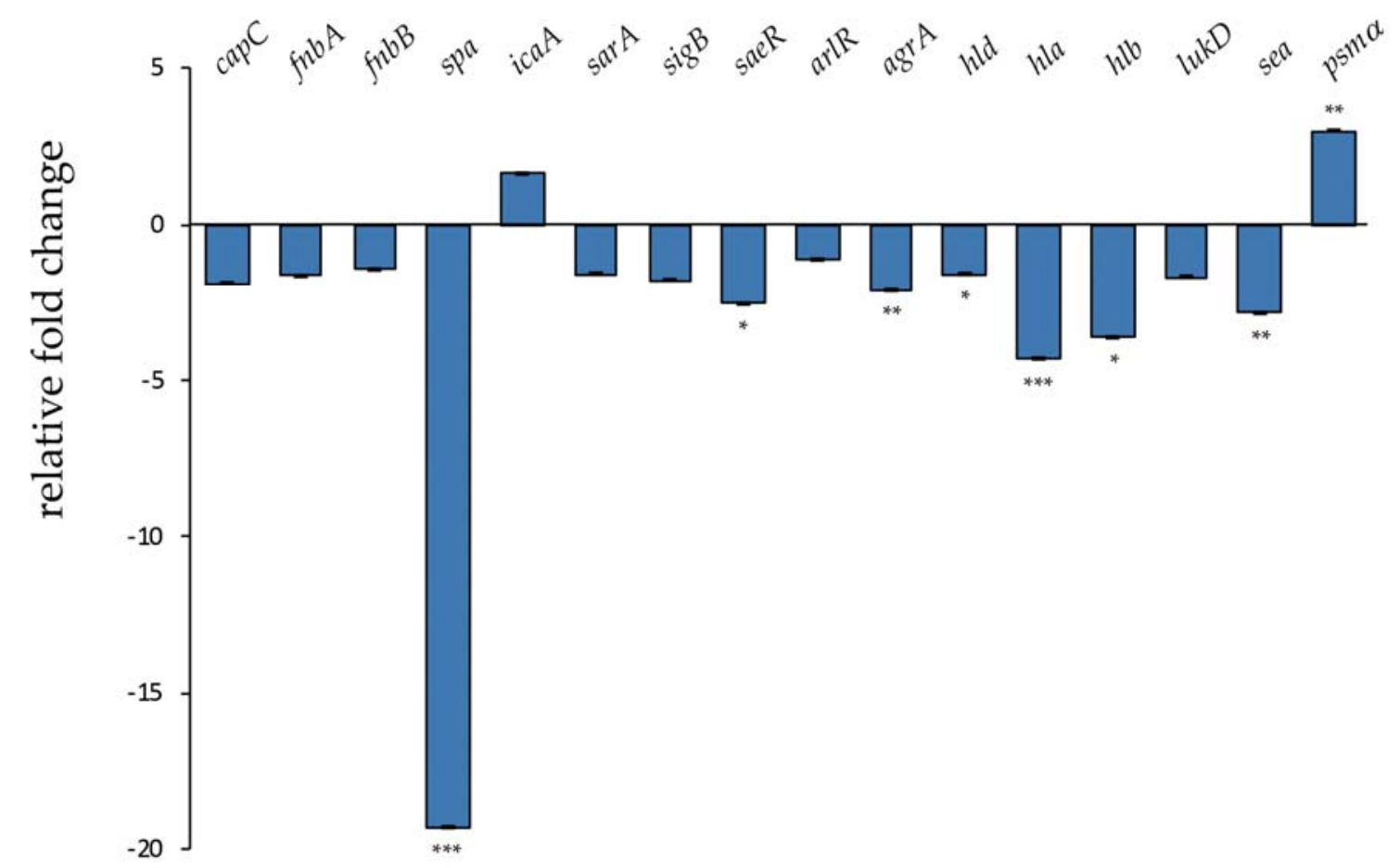

Figure 5. Transcriptional profiling of virulence factor genes in S. aureus ATCC 29213 after treatment with 1-NPDNJ determined by qRT-PCR. Data were normalized to rpoB expression. Fold-changes were calculated using treated versus untreated $S$. aureus cells. Asterisks indicate statistically significant differences between treated and untreated $S$. aureus cells $\left({ }^{*} p<0.05,{ }^{* *} p<0.01,{ }^{* * *} p<0.001\right)$. $c a p C$, capsule biosynthesis protein $C$; $f n b A$, fibronectin-binding protein $A$; $f n b B$, fibronectin-binding protein $\mathrm{B}$; spa, surface protein $\mathrm{A}$; $i c a A$, intercellular adhesion protein $\mathrm{A}$; sar $A$, staphylococcal accessory regulator $\mathrm{A} ; \operatorname{sig} B, \mathrm{RNA}$ polymerase sigma factor $\mathrm{B}$; saeR, response regulator SaeR; $a r l R$, response regulator ArlR; agr A, accessory gene regulator $\mathrm{A}$; $h l d$, delta-hemolysin; $h l a$, alpha-haemolysin; $h l b$, beta-haemolysin; $l u k D$, pore-forming leucocidin; sea, staphylococcal enterotoxin A; $p \sin \alpha$, alpha phenol-soluble modulin.

The transcriptional analysis was performed on samples that were harvested after treatment of S. aureus cells $\left(5 \times 10^{8} \mathrm{CFU} / \mathrm{mL}\right)$ at a sub-MIC concentration of L-NPDNJ for 3 hours. Untreated S. aureus cells grown in the same conditions were used as the control. No growth differences between treated and untreated cells were observed. In this type of experiment, genes with at least a 2-fold difference in the relative transcript levels and with a $P$ value of $<0.05$ were considered significant. As shown in Figure 5, the expression of about half of the tested genes was affected by L-NPDNJ treatment. 
The $S$. aureus virulence arises from the combination of a comprehensive array of virulence determinants including surface-associated proteins, exotoxins, enterotoxins and superantigens [8]. The S. aureus hemolysins alpha-toxin (Hla), beta-toxin ( $\mathrm{Hlb}$ ) and phenol-soluble modulins (PSMs) all cause the lysis of eukaryotic cells $[41,42]$ and may also contribute to the formation of biofilms $[5,43,44]$.

Mounting evidence identifies $S$. aureus toxins as potential targets of anti-virulence therapy $[45,46]$. In agreement with this, our results showed that the treatment of $S$. aureus cells with L-NPDNJ decreased significantly the expression of the $h l a, h l b$ and sea (encoding enterotoxin A) genes (Figure 5). Alpha toxin, a small pore-forming toxin, is a potent secreted cytolysin essential to the development of serious infections, including skin and soft tissue infections, pneumonia and bacteremia [41,47]. Hla is also required for cell-cell interactions during biofilm formation and is employed by $S$. aureus to evade the host immune system [48]. Many molecules can suppress Hla production by S. aureus or inhibit the self-assembly of Hla [49]. Beta toxin, a sphingomyelinase toxic for different types of human cells, forms an insoluble nucleoprotein in the biofilm matrix and stimulates biofilm formation in vivo, which is an important process occurring during infective endocarditis [44]. The staphylococcal enterotoxin $\mathrm{A}$ is the toxin most frequently reported to cause staphylococcal food poisoning [50]. It has been suggested that SEA may be involved during the early phases of colonization [51]. Our data are in accordance with a recent report, showing that both baicalin and thymol treatments reduced sea and hla levels [52,53].

In contrast with the effect observed on the expression of $h l a$ and $h l b$, we found that the treatment with L-NPDNJ resulted in the upregulation of the $p s m$ gene expression. PSMs genes belong to a novel family of toxins and play multiple roles during $S$. aureus pathogenesis, which typically involve blood cell lysis and biofilm development $[5,54]$. PSMs are small amphipathic peptides that can also disrupt cellular interactions within biofilms, facilitating the structuring and detachment of staphylococcal biofilms [42]. PSMs exhibit cytolytic activity against eukaryotic cells and this effect is diminished in human serum [9]. A recent paper reported low concentrations of both the clindamycin- and secalonic acid D-induced psm gene expression in S. aureus planktonic cells $[55,56]$. Overall, the downregulation of the expression of toxin genes observed during treatment with L-NPDNJ and other antimicrobials may reduce the damage of eukaryotic cells and/or biofilm formation of S. auerus.

In addition to the downregulation of toxin genes, L-NPDNJ was effective in decreasing the transcription of the spa gene (-19.3-fold), encoding surface protein A, whereas no significant changes were observed in the fibronectin binding protein A $(f n b A)$ and $B(f n b B)$ gene expressions (Figure 5). Moreover, L-NPDNJ has no effect on the expression of $i c a A$, which encodes for a transmembrane glucosyltransferase synthetizing polysaccharide intercellular adhesin (PIA) oligomers [57] (Figure 5). Protein A binds the Fc region of IgG, which may serve to limit infections in vivo [58]. Protein A is also involved in S. aureus host colonization inducing aggregation and biofilm development $[58,59]$. Thus, the decreased spa expression observed after L-NPDNJ treatment might contribute to the decrease in biofilm formation. Similarly, the benzimidazole derivative UM-C162 exhibits antivirulence and antibiofilm activities through the downregulation of $h l b$, spa virulence-associated genes and the saeR response regulator [60]. In addition, the benzimidazole-derived molecule ABC- 1 inhibits biofilm formation primarily by reducing the spa expression and accumulation of PIA on the cell surface without affecting the transcription of the icaA gene [61]. Recently, Hassan et al. [25] showed that D-DNJ downregulates a panel of genes encoding for glucosyltransferases involved in the synthesis of glucans $(g t f C, g t f D, g b p B)$, surface protein $(s p a P)$ and the quorum-sensing regulatory gene $(c o m D E)$, which are critical for $S$. mutans adherence to the tooth surface and virulence.

Finally, we observed that the treatment with L-NPDNJ reduced the expression of genes encoding for two global regulators of $S$. aureus virulence, the accessory gene regulator A (AgrA) and response regulator SaeR (Figure 5). The quorum-sensing system agr plays a key role in the regulation of $S$. aureus virulence genes [62]. The agr operon regulates both biofilm formation and the production of toxins, such as hemolysin (Hla and Hlb), enterotoxins and SpA [63-65]. PSMs are positively regulated by the direct binding of AgrA to the its promoter region [66] and negatively by the direct binding of the transcriptional regulator MgrA to the promoter region [67]. The staphylococcal accessory 
regulator (SarA) and the small RNA Teg41 can also influence the expression of PSMs $[42,68]$. In most strains of $S$. aureus, the agr system activates the transcription of the two-component system SaeRS [69]. SaeRS controls the expression of major virulence genes, including cell wall proteins (such as Spa and $\mathrm{FnbA}$ ) and secreted toxins (such as HlA and $\mathrm{Hlb}$ ), probably through direct interaction with these target genes [70,71]. The upregulation of virulence genes by SaeRS facilitates $S$. aureus survival following neutrophil evasion and pathogenesis [72,73]. It is possible that the downregulation of the agr $A$ and saeR genes could contribute to the downregulation of the other virulence genes tested, reducing the deleterious effects that occur in S. aureus infections.

Overall, our data demonstrate that L-NPDNJ inhibits the expression of important virulence and global regulator genes in S. aureus, attenuating probably the virulence of this pathogen. Future studies will be necessary to establish the molecular mechanism responsible for the effect of L-NPDNJ on S. aureus planktonic growth and biofilm formation.

\section{Materials and Methods}

\subsection{Chemicals and Reagents}

All chemicals and solvents were used with the highest degree purity and without further purification (Sigma-Aldrich, Alfa Aesar, VWR). TLC monitoring was used to follow the reaction course (F254 Merck silica gel plate) by exposure to ultraviolet radiation, iodine vapor and chromic mixture. Intermediates and final products were characterized by NMR analysis (NMR spectrometers: Bruker DRX and Bruker AVANCE $400 \mathrm{MHz}$ ). Compound purity was analyzed by elemental analysis (CHNS). Synthesis of iminosugars was accomplished as previously reported [21,34]. Iminosugars were dissolved in ultrapure DNase/RNase-free distilled water to the concentration of $20 \mathrm{mg} / \mathrm{mL}$.

\subsection{Bacterial Strains and Growth Conditions}

S. aureus ATCC 29213 and S. aureus clinical isolates described by us previously $[39,74]$ were grown overnight at $37{ }^{\circ} \mathrm{C}$ on Trypticase soy agar (TSA) with $5 \%$ sheep blood. The MIC of oxacillin was determined by a broth microdilution method according to the recommended procedures by the Clinical and Laboratory Standards Institute [75]. Methicillin-resistant S. aureus (MRSA) isolates (Table S1) were screened for the presence of staphylococcal cassette chromosome mec (SCCmec) using the Xpert MRSA kit (Cepheid, Sunnyvale, CA, USA).

\subsection{Determination of Minimum Inhibitory Concentration (MIC) and Minimum Bactericidal Concentration $(M B C)$}

MIC and MBC values of iminosugars were determined by a broth microdilution method as previously described [76]. Briefly, $180 \mu \mathrm{L}$ of cation-adjusted Mueller-Hinton broth (CA-MHB) containing serially diluted DNJ derivatives was inoculated with a $5 \times 10^{5}$ colony forming unit (CFU) and incubated at $37^{\circ} \mathrm{C}$ for $18-24 \mathrm{~h}$ under shaking ( $300 \mathrm{rpm}$ ). The final concentration of the tested compounds ranged from 1000 to $16 \mu \mathrm{g} / \mathrm{mL}$. Non-treated bacteria were used as controls. All tests were performed in triplicate and repeated three times.

\subsection{Time Killing Assay}

The time-killing kinetics of L-NPDNJ were determined against the S. aureus ATCC 29213 strain, as previously described [77]. A bacterial inoculum (approximately $5 \times 10^{6} \mathrm{CFU} / \mathrm{mL}$ ) was added to tubes containing different concentrations of L-NPDNJ $(512,256$ and $128 \mu \mathrm{g} / \mathrm{mL})$, and incubated at $37^{\circ} \mathrm{C}$ under shaking (300 rpm). A tube without L-NPDNJ was used as the growth control. A $50 \mu \mathrm{L}$ aliquot was removed from the bacterial culture at $0,1,2,3,4,5,7,8$ and $24 \mathrm{~h}$ and serial 10-fold dilutions of these cultures were plated on TSA for the determination of CFU/mL. All experiments were repeated three times. 


\subsection{Checkerboard Assay}

Tests were carried out using the microbroth checkerboard method according to the previously reported method [38]. Serial dilutions of L-NPDNJ $(256-8 \mu \mathrm{g} / \mathrm{mL}$ in sterile water) were prepared and combined with serial dilutions of gentamicin $(512-1 \mu \mathrm{g} / \mathrm{mL}$ in sterile water) or oxacillin $(256-0.5 \mu \mathrm{g} / \mathrm{mL}$ in sterile water). Subsequently, each of the different concentrations of antibiotics and of L-NPDNJ was added to each well of the microtiter plate containing approximately $5 \times 10^{6} \mathrm{CFU} / \mathrm{mL}$ of the S. aureus isolate 00717. The plates were then incubated at $37^{\circ} \mathrm{C}$ for $18-24 \mathrm{~h}$. The combined effects were then determined by calculating the fractional inhibitory concentration (FIC) index as follows: $\mathrm{FICI}=\mathrm{FIC}_{\mathrm{A}}+$ FIC $_{B}$, where FIC $_{A}$ is the ratio of the MIC of the L-NPDNJ combination and the MIC of L-NPDNJ alone and $\mathrm{FIC}_{\mathrm{B}}$ is the ratio of the MIC of the antibiotic in combination and the MIC of the antibiotic alone. The FIC index is interpreted as synergy (FICI $\leq 0.5$ ), additive (FICI $>0.5$ to $\leq 1.0$ ), indifference (FICI $>1.0$ to $\leq 2.0$ ) and antagonism (FICI $>2.0$ ) [38,78]. All experiments were repeated three times.

\subsection{Biofilm Assay}

Biofilm formation was examined using a crystal violet (CV) staining assay and confocal laser scanning microscopy (CLSM), according to the previously reported method [79]. The $0.5 \mathrm{McFarland}$ of bacterial cultures was diluted 1:100 in TSB supplemented with $0.5 \%$ glucose. Then, $5 \times 10^{6}$ cells $/ \mathrm{mL}$ was transferred into a 96-well flat-bottomed polystyrene microtiter plate containing $100 \mu \mathrm{L}$ of scalar doses of L-NPDNJ (ranging from 64 to $0.5 \mu \mathrm{g} / \mathrm{mL}$ and 64 to $32 \mu \mathrm{g} / \mathrm{mL}$ in CV and CLSM assays, respectively) and incubated at $37^{\circ} \mathrm{C}$ for $24 \mathrm{~h}$. Non-treated bacteria were incubated with $100 \mu \mathrm{L}$ of broth and used as the control. The culture supernatant was gently discarded, the wells were washed twice with phosphate-buffered saline (PBS) $1 \times \mathrm{pH} 7.4$ and the biofilms were stained with $200 \mu \mathrm{L}$ of $0.1 \%$ crystal violet for $15 \mathrm{~min}$. The wells were washed twice with PBS 1X, and dye was re-eluted with $100 \%$ ethanol. The absorbance was measured at $595 \mathrm{~nm}$ using a microplate reader (Bio-Rad Laboratories S.r.l.). All data points are expressed as means \pm SDs of three separate experiments performed in triplicate.

\subsection{RNA Purification and Real-Time RT-PCR}

S. aureus ATCC 29213 cells were grown at $37^{\circ} \mathrm{C}$ at $200 \mathrm{rpm}$ to the exponential phase $\left(\mathrm{OD}_{600}=0.4\right)$ and were subsequently split into two tubes and incubated in the presence or absence of L-NPDNJ at the concentration of $64 \mu \mathrm{g} / \mathrm{mL}$ for a further $3 \mathrm{~h}$. Total RNA was isolated from three independent cultures according to the previously reported method [80]. The cDNA was synthesized using QuantiTect Reverse Transcription Kit (Qiagen), according to the manufacturer's protocol. Real-time RT-PCR assays were performed by using a SYBR Green master mix (Applied Biosystems) as previously described [81]. The expressions of target genes were normalized using the rpoB gene as the housekeeping gene. The fold-change of the gene expression level was calculated using the $2-{ }^{\Delta \Delta C T}$ method [82]. All experiments were performed three times in triplicate. The primers used in the qRT-PCR experiments are reported in Table 3.

\subsection{Statistical Analysis}

All statistical analyses were carried out using GraphPad Prism version 8.0 for Windows (GraphPad Software, San Diego, CA, USA). All experiments were performed at least three times and the results are shown as means \pm SD. Differences between mean values were tested for significance by performing two-tailed Student's t-tests. A $P$ value $<0.05$ was considered to be statistically significant. 
Table 3. Gene target list and oligonucleotide sequences.

\begin{tabular}{|c|c|c|c|}
\hline Gene & Forward Primer $\left(5^{\prime}-3^{\prime}\right)$ & Reverse Primer (5'-3') & Reference \\
\hline $\operatorname{agr} \mathrm{A}$ & TGCGAAGACGATCCAAAAC & TTTAGCTTGCTCAAGCACCTC & [39] \\
\hline $\operatorname{arlR}$ & AGTTGCTGGGCTTGATTACG & ATCCTTTTGTGGCTGACGAC & this study \\
\hline $\operatorname{capC}$ & CATCCAGAGCGGAATAAAGC & CGGAAATACCCGCTAATGAC & [39] \\
\hline fnbA & AAGCACAAGGACCAATCGAG & ACGCCATAATTACCGTGACC & this study \\
\hline$f n b \mathrm{~B}$ & GAACATGGTCAAGCACAAGG & ACGCCATAATTACCGTGACC & [39] \\
\hline hla & TCTTGGAACCCGGTATATGG & AGCGAAGTCTGGTGAAAACC & [39] \\
\hline$h l b$ & GTGCCAAAGCCGAATCTAAG & ATCAGCGCGTTTATATTGTCC & [39] \\
\hline hld & AAGGAAGGAGTGATTTCAATGG & TTTGTTCACTGTGTCGATAATCC & [79] \\
\hline$i c a A$ & ACGCAGCAGTAGTTCTTGTCG & TGACCATGTTGCGTAACCAC & this study \\
\hline$l u k \mathrm{D}$ & GTACTTAAGGCAGCCGGAAAC & CGCCCCAATAAAACTGTGAG & [39] \\
\hline $\operatorname{psm} \alpha$ & TCAAAAGCTTAATCGAACAATTCAC & AATGGCCCССТTCAAATAAG & [79] \\
\hline rpoB & ACAACCACTTGGCGGTAAAG & ATGCTTCAAGTGCCCATACC & [39] \\
\hline sae R & CCAAGGGAACTCGTTTTACG & ACGCATAGGGACTTCGTGAC & [39] \\
\hline sarA & TTGCTTTGAGTTGTTATCAATGG & CAATACAGCGAATTCTTCAAAGC & [79] \\
\hline sea & ATTGCCCTAACGTGGACAAC & TGCTCCCTGCAATTCAGAC & [39] \\
\hline $\operatorname{sig} \mathrm{B}$ & TGATCGCGAACGAGAAATC & ATTGCCGTTCTCTGAAGTCG & [39] \\
\hline spa & AGATGACCCAAGCCAAAGTG & CTTTCGGTGCTTGAGATTCATT & [39] \\
\hline
\end{tabular}

\section{Conclusions}

We have herein reported one of the earliest studies on the antimicrobial properties of $\mathrm{D}$ - and L-iminosugars, with a special focus on their effects on the growth, biofilm formation and virulence factor expression of $S$. aureus. Our results have brought to identify in the iminosugar L-NPDNJ a new antimicrobial drug against $S$. aureus because of its antibacterial activity at $128 \mu \mathrm{g} / \mathrm{mL}$ MIC and bactericidal effect at $2 \times$ MIC. Noteworthy, combination effects were observed when L-NPDNJ was administered with the marketed antimicrobial drugs gentamicin and oxacillin, leading to an enhancement or a restoration of the antibacterial activity, respectively. Further, sub-MIC concentrations of L-NPDNJ were able to inhibit the S. aureus biofilm formation. Even more intriguingly, an addictive effect was observed when mixing equimolar amounts of the enantiomeric iminosugars D- and L-NPDNJ, although in this case, the enhancement of the antimicrobial activity was less marked. Moreover, L-NPDNJ was found to inhibit the expression of virulence and global regulator genes. Overall, our data suggest that L-NPDNJ and most generally lipophilic L-iminosugars may represent new candidates for the anti-virulence therapy of $S$. aureus. Future studies will be necessary to evaluate the therapeutic use of L-NPDNJ during S. aureus infections.

Supplementary Materials: The following are available online at http://www.mdpi.com/2079-6382/9/6/362/s1, Table S1: Antibiotic susceptibility of clinical isolates used in this study, Table S2: MIC $(\mu \mathrm{g} / \mathrm{mL})$ and MBC $(\mu \mathrm{g} / \mathrm{mL})$ values of L-NPDNJ for clinical isolates used in this study.

Author Contributions: Conceptualization, E.D.G. and A.G.; methodology, A.V., A.E., A.M., M.D.F., V.D.I. and D.D.; formal analysis, E.D.G.; investigation, E.D.G., A.E., A.V.; data curation, A.G., R.Z. and E.D.G.; writing—original draft preparation, A.G., R.Z. and E.D.G.; supervision, A.G., R.Z. and E.D.G.; funding acquisition, R.Z. and A.G. All authors have read and agreed to the published version of the manuscript.

Funding: This research was funded in part by grant from the Italian Ministry of Education, University and Research (MIUR): PRIN2017 (Grant 2017SFBFER to RZ), and in part by Italian Cystic Fibrosis Research Foundation, grant number FFC \#20/2019 (adopted by Delegazione FFC di Pesaro con Delegazione FFC di Torino Rivarolo Canavese e Gruppo di sostegno FFC di Parma Fidenza, Gruppo di sostegno FFC di Melilli, Gruppo di sostegno FFC di Tremestieri). A.E. is a contract holder (\#20/2019).

Conflicts of Interest: The authors declare no conflict of interest. The funders had no role in the design of the study; in the collection, analyses, or interpretation of data; in the writing of the manuscript, or in the decision to publish the results. 


\section{References}

1. David, M.Z.; Daum, R.S. Treatment of Staphylococcus aureus infections. Rev. Microbiol. Immunol. 2017, 409, 325-383.

2. Turner, N.A.; Sharma-Kuinkel, B.K.; Maskarinec, S.A.; Eichenberger, E.M.; Shah, P.P.; Carugati, M.; Holland, T.L.; Fowler, V.G. Methicillin-resistant Staphylococcus aureus: An overview of basic and clinical research. Nat. Rev. Genet. 2019, 17, 203-218. [CrossRef] [PubMed]

3. Vestergaard, M.; Frees, D.; Ingmer, H. Antibiotic resistance and the MRSA problem. Microbiol. Spectr. 2019, 7, 747-765. [CrossRef] [PubMed]

4. Figueiredo, A.M.S.; Ferreira, F.; Beltrame, C.O.; Côrtes, M.F. The role of biofilms in persistent infections and factors involved in ica-independent biofilm development and gene regulation in Staphylococcus aureus. Crit. Rev. Microbiol. 2017, 2, 1-19. [CrossRef] [PubMed]

5. Otto, M. Staphylococcal infections: Mechanisms of biofilm maturation and detachment as critical determinants of pathogenicity. Annu. Rev. Med. 2013, 64, 175-188. [CrossRef]

6. Paharik, A.E.; Horswill, A.R. The staphylococcal biofilm: Adhesins, regulation, and host response. Microbiol. Spectr. 2016, 4, 529-566. [CrossRef]

7. Jenul, C.; Horswill, A.R. Regulation of Staphylococcus aureus virulence. Microbiol. Spectr. 2018, 6, 669-686. [CrossRef]

8. Tam, K.; Torres, V.J. Staphylococcus aureus secreted toxins and extracellular enzymes. Microbiol. Spectr. 2019, 7, 640-668. [CrossRef]

9. Peschel, A.; Otto, M. Phenol-soluble modulins and staphylococcal infection. Nat. Rev. Genet. 2013, 11, 667-673. [CrossRef]

10. Totsika, M. Disarming pathogens: Benefits and challenges of antimicrobials that target bacterial virulence instead of growth and viability. Futur. Med. Chem. 2017, 9, 267-269. [CrossRef]

11. Kane, T.L.; Carothers, K.E.; Lee, S.W. Virulence factor targeting of the bacterial pathogen Staphylococcus aureus for vaccine and therapeutics. Curr. Drug Targets 2018, 19, 111-127. [CrossRef] [PubMed]

12. Compain, P.; Martin, O.R. Iminosugars: From Synthesis to Therapeutic Applications; John Wiley \& Sons, Ltd.: Chichester, UK, 2007; ISBN 9780470517437.

13. Wang, H.; Shen, Y.; Zhao, L.; Ye, Y. 1-Deoxynojirimycin and its derivatives: A mini review of the literature. Curr. Med. Chem. 2020, 27, 1. [CrossRef] [PubMed]

14. Nash, R.J.; Kato, A.; Yu, C.-Y.; Fleet, G.W. Iminosugars as therapeutic agents: Recent advances and promising trends. Futur. Med. Chem. 2011, 3, 1513-1521. [CrossRef] [PubMed]

15. Platt, F.M.; d'Azzo, A.; Davidson, B.L.; Neufeld, E.F.; Tifft, C.J. Lysosomal storage diseases. Nat. Rev. Dis. Prim. 2018, 4, 1-25. [CrossRef]

16. Fiaux, H.; Popowycz, F.; Favre, S.; Schütz, C.; Vogel, P.; Gerber-Lemaire, S.; Juillerat-Jeanneret, L. Functionalized pyrrolidines inhibit $\alpha$-mannosidase activity and growth of human glioblastoma and melanoma cells. J. Med. Chem. 2005, 48, 4237-4246. [CrossRef]

17. Evans, G.B.; Tyler, P.C.; Schramm, V.L. Immucillins in infectious diseases. ACS Infect. Dis. 2017, 4, 107-117. [CrossRef]

18. Alonzi, D.S.; Scott, K.; Dwek, R.A.; Zitzmann, N. Iminosugar antivirals: The therapeutic sweet spot. Biochem. Soc. Trans. 2017, 45, 571-582. [CrossRef]

19. Dechecchi, M.C.; Nicolis, E.; Norez, C.; Bezzerri, V.; Borgatti, M.; Mancini, I.; Rizzotti, P.; Ribeiro, C.M.; Gambari, R.; Becq, F.; et al. Anti-inflammatory effect of miglustat in bronchial epithelial cells. J. Cyst. Fibros. 2008, 7, 555-565. [CrossRef]

20. Best, D.; Jenkinson, S.F.; Saville, A.W.; Alonzi, D.S.; Wormald, M.; Butters, T.; Norez, C.; Becq, F.; Blériot, Y.; Adachi, I.; et al. Cystic fibrosis and diabetes: IsoLAB and isoDAB, enantiomeric carbon-branched pyrrolidine iminosugars. Tetrahedron Lett. 2010, 51, 4170-4174. [CrossRef]

21. De Fenza, M.; D’Alonzo, D.; Esposito, A.; Munari, S.; Loberto, N.; Santangelo, A.; Lampronti, I.; Tamanini, A.; Rossi, A.; Ranucci, S.; et al. Exploring the effect of chirality on the therapeutic potential of N-alkyl-deoxyiminosugars: Anti-inflammatory response to Pseudomonas aeruginosa infections for application in CF lung disease. Eur. J. Med. Chem. 2019, 175, 63-71. [CrossRef] 
22. Esposito, A.; D’Alonzo, D.; De Fenza, M.; De Gregorio, E.; Tamanini, A.; Lippi, G.; Dechecchi, M.C.; Guaragna, A. Synthesis and therapeutic applications of iminosugars in cystic fibrosis. Int. J. Mol. Sci. 2020, 21, 3353. [CrossRef] [PubMed]

23. Greimel, P.; Spreitz, J.; Stutz, A.; Wrodnigg, T. Iminosugars and relatives as antiviral and potential anti-infective agents. Curr. Top. Med. Chem. 2003, 3, 513-523. [CrossRef] [PubMed]

24. Islam, B.; Khan, S.N.; Haque, I.; Alam, M.; Mushfiq, M.; Khan, A.U. Novel anti-adherence activity of mulberry leaves: Inhibition of Streptococcus mutans biofilm by 1-deoxynojirimycin isolated from Morus alba. J. Antimicrob. Chemother. 2008, 62, 751-757. [CrossRef] [PubMed]

25. Hasan, S.; Singh, K.; Danisuddin, M.; Verma, P.K.; Khan, A.U. Inhibition of major virulence pathways of streptococcus mutans by quercitrin and deoxynojirimycin: A synergistic approach of infection control. PLOS ONE 2014, 9, e91736. [CrossRef]

26. Yoo, Y.; Seo, D.-H.; Lee, H.; Cho, E.-S.; Song, N.-E.; Nam, T.G.; Nam, Y.-D.; Seo, M.-J. Inhibitory effect of Bacillus velezensis on biofilm formation by Streptococcus mutans. J. Biotechnol. 2019, 298, 57-63. [CrossRef]

27. Strus, M.; Mikołajczyk, D.; Machul, A.; Heczko, P.; Chronowska, A.; Stochel, G.; Gallienne, E.; Nicolas, C.; Martin, O.R.; Kyzioł, A. Effects of the selected iminosugar derivatives on pseudomonas aeruginosa biofilm formation. Microb. Drug Resist. 2016, 22, 638-645. [CrossRef]

28. Horne, G.; Wilson, F.X.; Tinsley, J.; Williams, D.H.; Storer, R. Iminosugars past, present and future: Medicines for tomorrow. Drug Discov. Today 2011, 16, 107-118. [CrossRef]

29. D'Alonzo, D.; Guaragna, A.; Palumbo, G. Glycomimetics at the mirror: Medicinal chemistry of L-iminosugars. Curr. Med. Chem. 2009, 16, 473-505. [CrossRef]

30. Ghisaidoobe, A.; Bikker, P.; De Bruijn, A.C.J.; Godschalk, F.D.; Rogaar, E.; Guijt, M.C.; Hagens, P.; Halma, J.M.; Hart, S.M.V.; Luitjens, S.B.; et al. Identification of potent and selective glucosylceramide synthase inhibitors from a library of N-alkylated iminosugars. ACS Med. Chem. Lett. 2010, 2, 119-123. [CrossRef]

31. Asano, N. Iminosugars: The potential of carbohydrate analogs. Carbohydr. Chem. State Art Chall. Drug Dev. 2015, 279-301. [CrossRef]

32. Jenkinson, S.F.; Fleet, G.; Nash, R.J.; Koike, Y.; Adachi, I.; Yoshihara, A.; Morimoto, K.; Izumori, K.; Kato, A. Looking-glass synergistic pharmacological chaperones: DGJ and L-DGJ from the enantiomers of tagatose. Org. Lett. 2011, 13, 4064-4067. [CrossRef] [PubMed]

33. Rountree, J.S.S.; Butters, T.; Wormald, M.; Boomkamp, S.D.; Dwek, R.A.; Asano, N.; Ikeda, K.; Evinson, E.L.; Nash, R.J.; Fleet, G. Design, synthesis, and biological evaluation of enantiomeric $\beta$-N-acetylhexosaminidase inhibitors LABNAc and DABNAc as potential agents against Tay-Sachs and Sandhoff disease. Chem. Med. Chem. 2009, 4, 378-392. [CrossRef] [PubMed]

34. D'Alonzo, D.; De Fenza, M.; Porto, C.; Iacono, R.; Huebecker, M.; Cobucci-Ponzano, B.; Priestman, D.A.; Platt, F.M.; Parenti, G.; Moracci, M.; et al. N-Butyl-1-deoxynojirimycin (1-NBDNJ): Synthesis of an allosteric enhancer of $\alpha$-glucosidase activity for the treatment of pompe disease. J. Med. Chem. 2017, 60, 9462-9469. [CrossRef] [PubMed]

35. Caputo, R.; Ciriello, U.; Festa, P.; Guaragna, A.; Palumbo, G.; Pedatella, S. Stereoselective synthesis of fully protected (S)-1,7-dioxaspiro[5,5]undec-4-ene derivatives of sugars. Eur. J. Org. Chem. 2003, 2617-2621. [CrossRef]

36. D'Alonzo, D.; Guaragna, A.; Van Aerschot, A.; Herdewijn, P.; Palumbo, G. Toward L-homo-DNA: Stereoselective de novo synthesis of $\beta$-L-erythro-hexopyranosyl nucleosides. J. Org. Chem. 2010, 75, 6402-6410. [CrossRef]

37. Levison, M.E. Pharmacodynamics of antimicrobial drugs. Infect. Dis. Clin. 2004, 18, 451-465. [CrossRef]

38. Hall, M.; Middleton, R.; Westmacott, D. The fractional inhibitory concentration (FIC) index as a measure of synergy. J. Antimicrob. Chemother. 1983, 11, 427-433. [CrossRef]

39. Vollaro, A.; Esposito, A.; Antonaki, E.; Iula, V.D.; D'Alonzo, D.; Guaragna, A.; De Gregorio, E. Steroid derivatives as potential antimicrobial agents against Staphylococcus aureus planktonic cells. Microorganisms 2020, 8, 468. [CrossRef]

40. Bouton, J.; Van Hecke, K.; Rasooly, R.; Van Calenbergh, S. Synthesis of pyrrolidine-based hamamelitannin analogues as quorum sensing inhibitors in Staphylococcus aureus. Beilstein J. Org. Chem. 2018, 14, 2822-2828. [CrossRef]

41. Von Hoven, G.; Qin, Q.; Neukirch, C.; Husmann, M.; Hellmann, N. Staphylococcus aureus $\alpha$-toxin: Small pore, large consequences. Biol. Chem. 2019, 400, 1261-1276. [CrossRef] [PubMed]

42. Li, S.; Huang, H.; Rao, X.; Chen, W.; Wang, Z.; Hu, X. Phenol-soluble modulins: Novel virulence-associated peptides of staphylococci. Futur. Microbiol. 2014, 9, 203-216. [CrossRef] [PubMed] 
43. Anderson, M.J.; Lin, Y.-C.; Gillman, A.; Parks, P.J.; Schlievert, P.M.; Peterson, M.L. Alpha-toxin promotes Staphylococcus aureus mucosal biofilm formation. Front. Microbiol. 2012, 2, 64. [CrossRef] [PubMed]

44. Huseby, M.J.; Kruse, A.C.; Digre, J.; Kohler, P.L.; Vocke, J.A.; Mann, E.E.; Bayles, K.W.; Bohach, G.A.; Schlievert, P.M.; Ohlendorf, U.H.; et al. Beta toxin catalyzes formation of nucleoprotein matrix in staphylococcal biofilms. Proc. Natl. Acad. Sci. USA 2010, 107, 14407-14412. [CrossRef] [PubMed]

45. Kong, C.; Neoh, H.-M.; Nathan, S. Targeting Staphylococcus aureus toxins: A potential form of anti-virulence therapy. Toxins 2016, 8, 72. [CrossRef] [PubMed]

46. Cheung, G.Y.C.; Otto, M. The potential use of toxin antibodies as a strategy for controlling acute Staphylococcus aureus infections. Expert Opin. Ther. Targets 2012, 16, 601-612. [CrossRef]

47. Xiong, Y.Q.; Willard, J.; Yeaman, M.R.; Cheung, A.L.; Bayer, A.S. Regulation of Staphylococcus aureus $\alpha$-toxin gene (hla) expression by agr, sarA, and sae in vitro and in experimental infective endocarditis. J. Infect. Dis. 2006, 194, 1267-1275. [CrossRef] [PubMed]

48. Caiazza, N.C.; O'Toole, G.A. Alpha-toxin is required for biofilm formation by Staphylococcus aureus. J. Bacteriol. 2003, 185, 3214-3217. [CrossRef]

49. Wu, S.-C.; Liu, F.; Zhu, K.; Shen, J.-Z. Natural products that target virulence factors in antibiotic-resistant Staphylococcus aureus. J. Agric. Food Chem. 2019, 67, 13195-13211. [CrossRef]

50. Betley, M.; Mekalanos, J. Staphylococcal enterotoxin A is encoded by phage. Science 1985, 229, $185-187$. [CrossRef]

51. Schlievert, P.M.; Bohach, G. Staphylococcal and streptococcal superantigens: An update. In Superantigens: Molecular Basis for the Role in Human Diseases; Fraser, J.D., Kobt, M., Eds.; ASM Press: Washington, DC, USA, 2007; pp. 21-36.

52. Chen, Y.; Liu, T.; Wang, K.; Hou, C.; Cai, S.; Huang, Y.; Du, Z.; Huang, H.; Kong, J.; Chen, Y. Baicalein inhibits Staphylococcus aureus biofilm formation and the quorum sensing system in vitro. PLoS ONE 2016, 11, e0153468. [CrossRef]

53. Qiu, J.; Wang, D.; Xiang, H.; Feng, H.; Jiang, Y.; Xia, L.; Dong, J.; Lu, J.; Yu, L.; Deng, X. Subinhibitory concentrations of thymol reduce enterotoxins A and B and $\alpha$-hemolysin production in Staphylococcus aureus isolates. PLOS ONE 2010, 5, e9736. [CrossRef]

54. Periasamy, S.; Chatterjee, S.S.; Cheung, G.Y.C.; Otto, M. Phenol-soluble modulins in staphylococci: What are they originally for? Commun. Integr. Biol. 2012, 5, 275-277. [CrossRef] [PubMed]

55. Schilcher, K.; Andreoni, F.; Haunreiter, V.D.; Seidl, K.; Hasse, B.; Zinkernagel, A.S. Modulation of Staphylococcus aureus biofilm matrix by subinhibitory concentrations of clindamycin. Antimicrob. Agents Chemother. 2016, 60, 5957-5967. [CrossRef] [PubMed]

56. Wang, J.; Nong, X.-H.; Zhang, X.-Y.; Xu, X.-Y.; Amin, M.; Qi, S.-H. Screening of anti-biofilm compounds from marine-derived fungi and the effects of secalonic acid D on Staphylococcus aureus biofilm. J. Microbiol. Biotechnol. 2017, 27, 1078-1089. [CrossRef] [PubMed]

57. Gerke, C.; Kraft, A.; Süßmuth, R.; Schweitzer, O.; Götz, F. Characterization of the N-acetylglucosaminy ltransferase activity involved in the biosynthesis of the Staphylococcus epidermidis polysaccharide intercellular adhesin. J. Biol. Chem. 1998, 273, 18586-18593. [CrossRef]

58. Atkins, K.L.; Burman, J.D.; Chamberlain, E.S.; Cooper, J.E.; Poutrel, B.; Bagby, S.; Jenkins, A.T.A.; Feil, E.; Elsen, J.M.V.D.; Jenkins, A.T.A. S. aureus IgG-binding proteins SpA and Sbi: Host specificity and mechanisms of immune complex formation. Mol. Immunol. 2008, 45, 1600-1611. [CrossRef]

59. Merino, N.; Toledo-Arana, A.; Vergara-Irigaray, M.; Valle, J.; Solano, C.; Calvo, E.; Lopez, J.A.; Foster, T.J.; Penadés, J.R.; Lasa, I. Protein A-mediated multicellular behavior in Staphylococcus aureus. J. Bacteriol. 2008, 191, 832-843. [CrossRef]

60. Kong, C.; Chee, C.F.; Richter, K.; Thomas, N.; Rahman, N.A.; Nathan, S. Suppression of Staphylococcus aureus biofilm formation and virulence by a benzimidazole derivative, UM-C162. Sci. Rep. 2018, 8, 2758. [CrossRef]

61. Shrestha, L.; Kayama, S.; Sasaki, M.; Kato, F.; Hisatsune, J.; Tsuruda, K.; Koizumi, K.; Tatsukawa, N.; Yu, L.; Takeda, K.; et al. Inhibitory effects of antibiofilm compound 1 against Staphylococcus aureus biofilms. Microbiol. Immunol. 2016, 60, 148-159. [CrossRef]

62. Dunman, P.M.; Murphy, E.; Haney, S.; Palacios, D.; Tucker-Kellogg, G.; Wu, S.; Brown, E.L.; Zagursky, R.J.; Shlaes, D.; Projan, S.J. Transcription profiling-based identification ofStaphylococcus aureus genes regulated by the agrand/or sarA Loci. J. Bacteriol. 2001, 183, 7341-7353. [CrossRef] 
63. Goerke, C.; Fluckiger, U.; Steinhuber, A.; Zimmerli, W.; Wolz, C. Impact of the regulatory loci agr, sarA and sae of Staphylococcus aureus on the induction of alpha-toxin during device-related infection resolved by direct quantitative transcript analysis. Mol. Microbiol. 2001, 40, 1439-1447. [CrossRef] [PubMed]

64. Coelho, L.; Souza, R.R.; Ferreira, F.; Guimarães, M.A.; Ferreira-Carvalho, B.T.; Figueiredo, A.M.S.; Nozaki, S.; Ogawa, T. Agr RNAIII divergently regulates glucose-induced biofilm formation in clinical isolates of Staphylococcus aureus. Microbiology 2008, 154, 3480-3490. [CrossRef] [PubMed]

65. Gustafsson, E.; Nilsson, P.; Karlsson, S.; Arvidson, S. Characterizing the dynamics of the quorum-sensing system in Staphylococcus aureus. J. Mol. Microbiol. Biotechnol. 2004, 8, 232-242. [CrossRef] [PubMed]

66. Queck, S.Y.; Jameson-Lee, M.; Villaruz, A.E.; Bach, T.-H.L.; Khan, B.; Sturdevant, D.E.; Ricklefs, S.M.; Li, M.; Otto, M. RNAIII-independent target gene control by the agr quorum-sensing system: Insight into the evolution of virulence regulation in Staphylococcus aureus. Mol. Cell 2008, 32, 150-158. [CrossRef]

67. Jiang, Q.; Jin, Z.; Sun, B. MgrA negatively regulates biofilm formation and detachment by repressing the expression of psm operons in Staphylococcus aureus. Appl. Environ. Microbiol. 2018, 84. [CrossRef]

68. Zapf, R.; Wiemels, R.E.; Keogh, R.; Holzschu, D.L.; Howell, K.M.; Trzeciak, E.; Caillet, A.R.; King, K.A.; Selhorst, S.A.; Naldrett, M.J.; et al. The small RNA Teg41 regulates expression of the alpha phenol-soluble modulins and is required for virulence in Staphylococcus aureus. MBio 2019, 10, e02484-18. [CrossRef]

69. Geiger, T.; Goerke, C.; Mainiero, M.; Kraus, D.; Wolz, C. The virulence regulator sae of Staphylococcus aureus: Promoter activities and response to phagocytosis-related signals. J. Bacteriol. 2008, 190, 3419-3428. [CrossRef]

70. Liu, Q.; Yeo, W.; Bae, T. The SaeRS two-component system of Staphylococcus aureus. Genes 2016, 7, 81. [CrossRef]

71. Mainiero, M.; Goerke, C.; Geiger, T.; Gonser, C.; Herbert, S.; Wolz, C. Differential target gene activation by the Staphylococcus aureus two-component system saeRS. J. Bacteriol. 2009, 192, 613-623. [CrossRef]

72. Voyich, J.M.; Vuong, C.; Dewald, M.; Nygaard, T.K.; Kocianova, S.; Griffith, S.; Jones, J.; Iverson, C.; Sturdevant, D.E.; Braughton, K.R.; et al. The SaeR/S gene regulatory system is essential for innate immune evasion by Staphylococcus aureus. J. Infect. Dis. 2009, 199, 1698-1706. [CrossRef]

73. Flack, C.E.; Zurek, O.W.; Meishery, D.D.; Pallister, K.B.; Malone, C.L.; Horswill, A.R.; Voyich, J.M. Differential regulation of staphylococcal virulence by the sensor kinase SaeS in response to neutrophil-derived stimuli. Proc. Natl. Acad. Sci. USA 2014, 111, E2037-E2045. [CrossRef] [PubMed]

74. De Gregorio, E.; Roscetto, E.; Iula, V.D.; Martinucci, M.; Zarrilli, R.; Di Nocera, P.P.; Catania, M.R. Development of a real-time PCR assay for the rapid detection of Acinetobacter baumannii from whole blood samples. New Microbiol. 2015, 38, 251-257. [PubMed]

75. Clinical and Laboratory Standards Institute. CLSI document M07-A9. In Methods for Dilution Antimicrobial Susceptibility Tests for Bacteria That Grow Aerobically: Approved Standard-Ninth Edition; Clinical and Laboratory Standards Institute: Wayne, PA, USA, 2012.

76. Esposito, A.; De Gregorio, E.; De Fenza, M.; D'Alonzo, D.; Satawani, A.; Guaragna, A. Expeditious synthesis and preliminary antimicrobial activity of deflazacort and its precursors. RSC Adv. 2019, 9, 21519-21524. [CrossRef]

77. Esposito, A.; Vollaro, A.; Esposito, E.P.; D’Alonzo, D.; Guaragna, A.; Zarrilli, R.; De Gregorio, E. Antibacterial and antivirulence activity of glucocorticoid PYED-1 against Stenotrophomonas maltophilia. Antibiotics) 2020, 9 , 105. [CrossRef]

78. European Committee for Antimicrobial Susceptibility Testing (EUCAST) of the European Society of Clinical Microbiology and Infectious Diseases (ESCMID). Terminology relating to methods for the determination of susceptibility of bacteria to antimicrobial agents. Clin. Microbiol. Infect. 2000, 6, 503-508. [CrossRef]

79. Vollaro, A.; Esposito, A.; Esposito, E.P.; Zarrilli, R.; Guaragna, A.; De Gregorio, E. PYED-1 inhibits biofilm formation and disrupts the preformed biofilm of Staphylococcus aureus. Antibiotics 2020, 9, 240. [CrossRef]

80. De Gregorio, E.; Esposito, E.P.; Zarrilli, R.; Di Nocera, P.P. Contact-dependent growth inhibition proteins in Acinetobacter baylyi ADP1. Curr. Microbiol. 2018, 75, 1434-1440. [CrossRef]

81. Martinucci, M.; Roscetto, E.; Iula, V.D.; Votsi, A.; Catania, M.R.; De Gregorio, E. Accurate identification of members of the Burkholderia cepacia complex in cystic fibrosis sputum. Lett. Appl. Microbiol. 2016, 62, 221-229. [CrossRef]

82. Livak, K.J.; Schmittgen, T.D. Analysis of relative gene expression data using real-time quantitative PCR and the 2(-Delta Delta C(T)) method. Methods 2001, 25, 402-408. [CrossRef]

(C) 2020 by the authors. Licensee MDPI, Basel, Switzerland. This article is an open access article distributed under the terms and conditions of the Creative Commons Attribution (CC BY) license (http://creativecommons.org/licenses/by/4.0/). 